\title{
Commentary: MI VII: Cardiac tumor; CMRI I: The solution
}

\author{
Frank A. Baciewicz, Jr, MD
}

\footnotetext{
From the Department of Cardiothoracic Surgery, Michael and Marian Ilitch Department of Surgery, Wayne State University School of Medicine, Detroit, Mich.

Conflicts of Interest: None

No funding was provided.

Disclosures: Author has nothing to disclose with regard to commercial support.

Received for publication Sept 29, 2018; accepted for publication Oct 1, 2018; available ahead of print Nov 14, 2018.

Address for reprints: Frank A. Baciewicz, Jr, MD, Harper Hospital, 3990 John R, Detroit, MI 48201 (E-mail: fbaciewi@dmc.org).

J Thorac Cardiovasc Surg 2019;157:1923-4

$0022-5223 / \$ 36.00$

Copyright (C) 2018 by The American Association for Thoracic Surgery

https://doi.org/10.1016/j.jtcvs.2018.10.021
}

Although not as edge-of-your-seat thrilling as Tom Cruise's unraveling of international intrigue as agent Ethan Hunt in the Mission Impossible $(M I)$ spy series, ${ }^{1}$ cardiac magnetic resonance imagining (CMRI) offers a solution to the often difficult preoperative diagnosis of cardiac tumors.

With the plethora of central lines, central dialysis catheters, transvenous pacing leads, automatic internal defibrillator leads, and endocardial growths secondary to the opioid crisis, cardiac surgeons have been asked to evaluate increasing numbers of cardiac masses. Fortunately, thrombotic lesions, myxomas, and endocarditis-related masses can be diagnosed by echocardiography. Tumors such as lipoma or lipomatous hypertrophy can be diagnosed by their tissue characteristics on computed tomographic scan. For the subset of patients in whom echocardiography, computed tomographic scan, and clinical history are not helpful, Kassi and colleagues ${ }^{2}$ report in this issue of the Journal how they have applied CMRI parameters to differentiate benign from malignant cardiac tumors.

Before describing their results, Kassi and colleagues ${ }^{2}$ mention some caveats. Cardiac tumors are rare, with an incidence between $0.17 \%$ and $0.30 \%$ in autopsy series, ${ }^{3,4}$ most primary cardiac tumors are benign, ${ }^{5}$ and most cardiac tumors are metastatic. ${ }^{6,7}$ In fact, $10 \%$ to $20 \%$ of patients with terminal cancer have metastases to the heart or a malignant pericardial effusion. ${ }^{8,9}$ These metastatic cardiac lesions are rarely resected, and a pericardial effusion caused by metastatic disease is usually drained percutaneously.

Because the typical cardiac surgeon will rarely encounter a primary cardiac tumor other than a myxoma requiring resection, these CMRI sequences become an even more valuable diagnostic aid. The benign or malignant nature of the tumor will affect the surgical approach and possibly the recommendations regarding preoperative chemotherapy or immunotherapy for certain malignant tumors.

The peculiarities of cardiac tumors are reflected in the study's exclusions. Of the 130 patients referred to

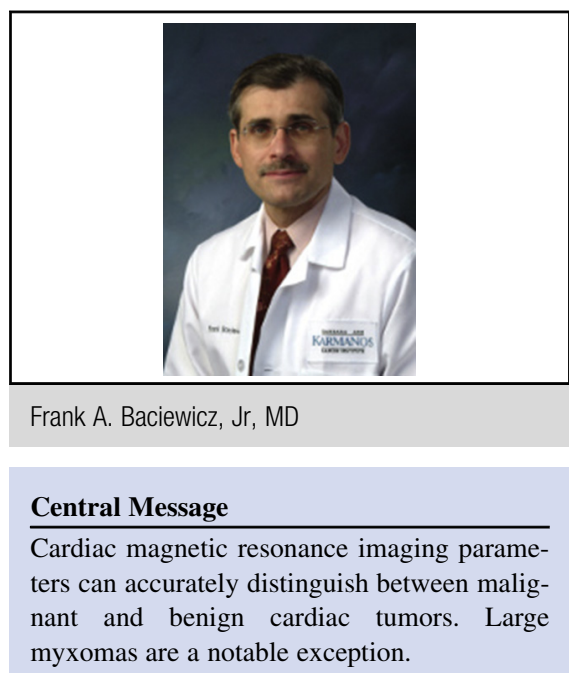

See Article page 1912.

Houston's DeBakey Heart Institute from 2009 through 2012 for CMRI, 28 had no detectable mass on CMRI (false positive or pseudotumor). From the remaining 102, Kassi and colleagues ${ }^{2}$ excluded an additional 36 patients: 18 with typical thrombi, 10 without final pathologic diagnosis, and 10 with papillary fibroelastomas, which are typically small and difficult to image both on echocardiography and on CMRI. This left 66 patients who formed the study population for tumor differentiation by CMRI. Of these 66 , only 54 had pathologic confirmation of their diagnosis, either by operation or biopsy. The patients who did not have a final pathologic diagnosis did not undergo operation or biopsy because they had cardiac masses characteristic of lipoma, ${ }^{3}$ cardiac masses characteristic of lipomatous hypertrophy, ${ }^{6}$ or obvious metastases from primary tumors, such as liver, colon, or renal tumors.

The 66 patients were the basis for the CMRI sequences, which defined 27 benign masses (41\%), and 39 malignant masses $(59 \%)$. The malignant tumors had irregular borders $(80 \%$ vs $26 \%)$, infiltrated the free wall or adjacent structures $(100 \%$ vs $0 \%)$, and were usually larger (5.0 vs $3.0 \mathrm{~cm}$ ). One exception to this size criterion was myxomas, which were benign and often larger than $3 \mathrm{~cm}$.

First-pass perfusion as a result of the tumor's vascularity was demonstrated in all malignant tumors (100\% vs 33\%). Late gadolinium enhancement secondary to apoptosis or necrosis in the mass was evident in all malignant tumors $(100 \%$ vs $59.3 \%)$. The malignant tumors typically had 
pericardial effusions ( $41 \%$ vs $7.4 \%$ ). Those patients with malignant tumors tended to be younger (51 vs 65 years), to be less likely to have arrhythmias, to be less likely to have coronary disease, and to have a lower ejection fraction.

The $100 \%$ sensitivity of both first-pass perfusion and late gadolinium enhancement discriminated malignant from benign tumors. By adding these to the other CMRI parameters, an algorithm was created that allows discrimination between malignant and benign cardiac tumors.

If one remains aware of the pitfalls, such as false-positive masses on echocardiogram and the frequency of thrombi, CMRI parameters can accurately differentiate malignant from benign cardiac tumors. As Ethan Hunt in $M I$ used all available resources, the cardiac surgeon should incorporate CMRI sequences for the diagnosis of benign or malignant cardiac tumors.

\section{References}

1. Mission Impossible, I-VI. Hollywood: Paramount Pictures.

2. Kassi M, Polsani V, Schutt RC, Wong S, Nabi F, Reardon MJ, et al. Differentiating benign from malignant cardiac tumors with cardiac magnetic resonance imaging. J Thorac Cardiovasc Surg. 2019;157: 1912-22.e2.

3. Patel SD, Peterson A, Bartczak A, Lee S, Chojnowski S, Gajewski P, et al. Primary cardiac angiosarcoma-a review. Med Sci Monit. 2014;20:103-9.

4. Reynen K. Cardiac myxomas. N Engl J Med. 1995;333:1610-7.

5. Silverman NA. Primary cardiac tumors. Ann Surg. 1980;91:127-38.

6. O'Donnell DH, Abbara S, Chaithiraphan V, Yared K, Killeen RP, Cury RC, et al. Cardiac Tumors: optimal cardiac MR sequences and spectrum of imaging appearances. AJR Am J Roentgenol. 2009;193:377-87.

7. Hoffmann U, Globits S, Schima W, Loewe C, Puig S, Oberhuber G, et al. Usefulness of magnetic resonance imaging of cardiac and paracardiac masses. Am J Cardiol. 2003;92:890-5.

8. Smith C. Tumors of the heart. Arch Pathol Lab Med. 1986;110:371-4.

9. McAllister HH, Fenoglio JJ Jr. Atlas of Tumor Pathology, Series 2: Tumors of the Cardiovascular System. Washington, DC: Armed Forces Institute of Pathology; 1978. 